\title{
RECONSTRUCCIÓN NASAL CON CARTÍLAGO COSTAL DE BANCO DE HUESO
}

\author{
María Alejandra Taborda MD*, Gustavo Romero MD**
}

\section{Resumen}

Reporte de diez pacientes con deformidad rinoseptal con distintas etiologías: traumáticas, infecciosas y quirúrgicas. La obstrucción nasal fue el principal síntoma, además de la deformidad estética. Todos acudieron a la consulta externa de otorrinolaringología del Hospital de San José de Bogotá DC. Se realizó reconstrucción nasal con cartílago costal de banco de hueso mediante técnica abierta. El seguimiento mínimo fue de siete meses y el máximo de dieciséis. Se evaluaron con registro fotográfico pre y posquirúrgico. No hubo infección del sitio operatorio ni extrusión del injerto. Las mejorías funcional y estética fueron evaluadas por la satisfacción del paciente y del cirujano como buenas o excelentes. La aplicabilidad de la técnica mostró buenos resultados en diferentes grupos etarios y etiológicos.

Palabras clave: reconstrucción nasal, deformidad rinoseptal, injerto de banco de hueso.

\section{NOSE RECONSTRUCTION WITH COSTAL CARTILAGE FROM A TISSUE BANK}

\section{Abstract}

Report on ten patients with rhinoseptal deformity of trauma, infection and unsuccessful surgery etiology. The main complaint was nasal obstruction besides aesthetic deformity. All were seen at the otolaryngology outpatient clinic at Hospital de San José, Bogotá DC. Reconstruction with costal cartilage obtained from a tissue bank was conducted by an open approach. Minimum follow-up duration was 7 weeks and maximum 16 weeks. Patients were assessed with pre and postsurgical photographs. No infection of the surgical site or graft extrusion was observed. Functional and aesthetic improvement was evaluated by patients and surgeons, rated good or excellent. The application of this technique yielded good results for different age groups and etiologies.

Key words: nasal reconstruction, rhinoseptal deformity, graft from a tissue bank.

Fecha recibido: agosto 24 de 2010 - Fecha aceptado: septiembre 3 de 2010

* Otorrinolaringóloga, Cirujana plástica facial y máxilofacial, Instructora Asistente. Fundación Universitaria de Ciencias de la Salud. Bogotá DC. Colombia.
** Residente IV Otorrinolaringología. Fundación Universitaria de Ciencias de la Saud. Bogotá DC. Colombia. 


\section{Introducción}

La reconstrucción nasal se considera la reina de todas las cirugías nasales por su alta complejidad, ya que desconocemos las condiciones en que se encuentran las estructuras anatómicas y cuáles deben ser restauradas.' En la sala quirúrgica cada caso resulta un reto debido a que el cirujano debehacergala de todos sus conocimientos para restituir la funcionalidad y la estética. De hecho, el diagnóstico final es intraquirúrgico y se debe tener la capacidad de resolver todas las alteraciones encontradas. El objetivo de la reconstrucción nasal se dirige al logro de una forma nasal estética balanceada y al restablecimiento de la función respiratoria. ${ }^{2}$ Las diferentes técnicas para lograr tales objetivos deben incluir la utilización de implantes, diversos tipos de suturas, cartílagos autólogos y homólogos. ${ }^{3}$

Debido a la gran deformidad estética y funcional en la mayoría de los casos no existe cartílago autólogo por lo cual debe recurrirse a bancos de tejidos ${ }^{4}$, los cuales proveen de excelente material osteocartilaginoso. Por ello, cada día son más usados en cirugías reconstructivas con excelentes resultados. ${ }^{5}$ Se presenta la experiencia en reconstrucción nasal con injerto de banco de hueso de cartílago costal en pacientes con deformidades rinoseptales y sus resultados funcionales y estéticos.

\section{Materiales y métodos}

Se realizó un estudio descriptivo prospectivo. Ingresaron casos consecutivos de pacientes adultos y jóvenes remitidos a la consulta externa del servicio de otorrinolaringología del Hospital de San José de Bogotá DC. entre abril 2008 y marzo 2009, quienes presentaban deformidad estética y funcional con gran deterioro del soporte nasal con afección de los 2/3 proximales septales, por lo cual tenían indicación inequívoca de injerto de banco de hueso, independiente de la etiología de la lesión. Se excluyeron pacientes que no disponían de tejido para lograr una adecuada cobertura inmediata. Todos firmaron el consentimiento informado previo al procedimiento quirúrgico.

En la valoración preoperatoria se consideraron las variables edad, género, tipo de defecto nasal, colapso alar, valvular, perforación septal y cirugía previa. Todos los procedimientos fueron realizados por el mismo cirujano. Se realizó reconstrucción nasal con cartílago costal homólogo del banco de huesos. Los tejidos seleccionados se cortaron y empacaron al vacío en tres bolsas de polietileno y almacenados en congeladores de alto poder a $-80^{\circ} \mathrm{C}$. La distribución y transporte del cartílago congelado se realizó en contenedores refrigerados con indicador de temperatura garantizando la preservación de la cadena de frío (Figura 1). El proceso de descongela-

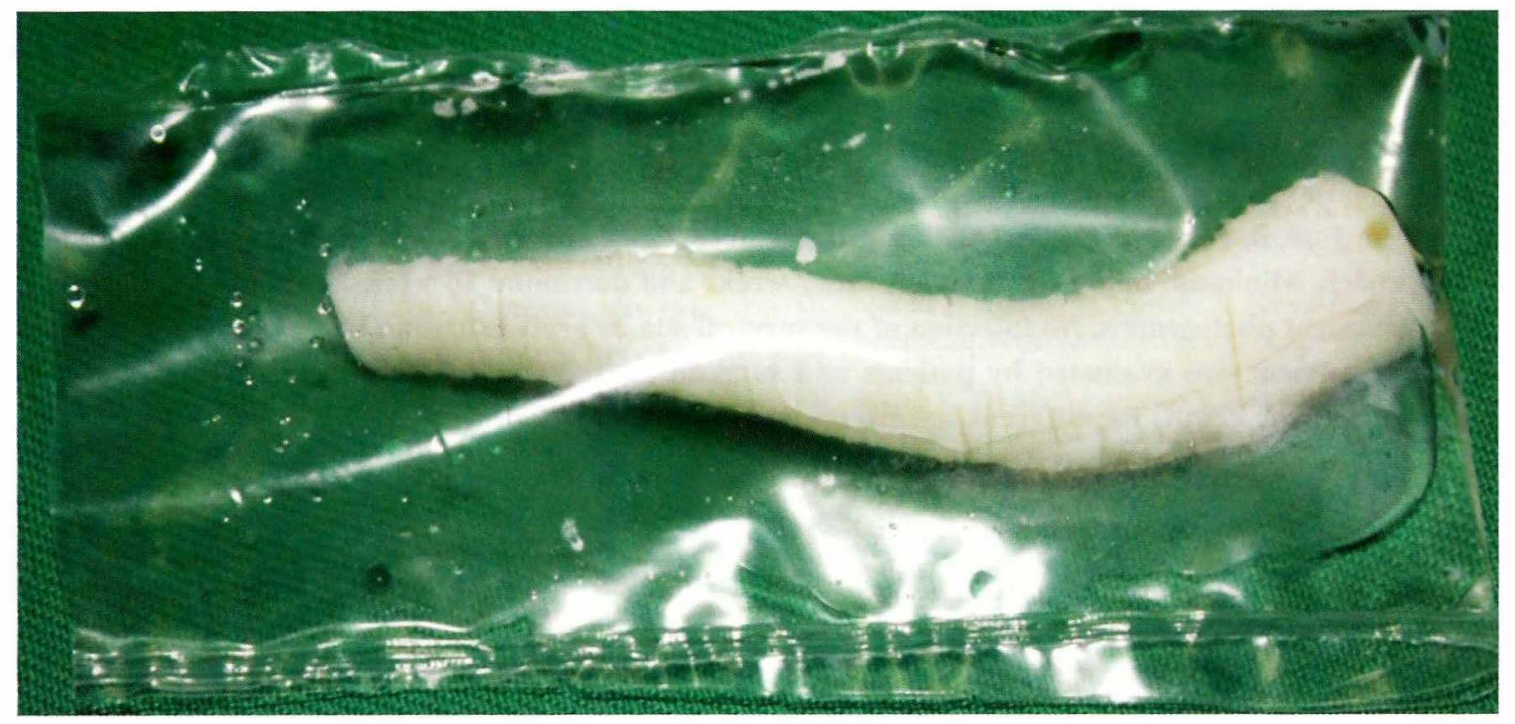

Figura I. Cartílago costal de banco de hueso. 
ción se realizó según protocolo en el momento mismo de la cirugía, utilizando solución salina estéril a una temperatura de $30^{\circ} \mathrm{C}$ durante diez a veinte minutos.

En el posoperatorio se evaluó la presencia de complicaciones (infección temprana y tardía, rechazo, extrusión, persistencia de perforación septal), resultado funcional dado por permeabilidad de vía aérea mediante examen físico y referencia del paciente, resultado estético medido como la satisfacción o insatisfacción tanto del paciente como del cirujano a los siete meses y el requerimiento de reintervención, dejando registro fotográfico.

\section{Técnica quirúrgica}

Se practicó reconstrucción nasal bajo anestesia general previa infiltración del nervionasaly la nariz con xilocaína al $1 \%$ con epinefrina, mediante septorrinoplastia abierta. A nivel del septum se realizó incisión hemitransfixiante derecha con disección de túneles superiores e inferiores y corrección de la septodesviación.

En la columnela se hace una incisión de $\mathrm{V}$ invertida con disección de la punta y el dorso nasal. ${ }^{6}$ Se liberan cartílagos laterales superiores comunicándose con túne- les superiores. Se toma injerto de cartílago costal de banco de hueso, porción medial, previamente tallado, apartando porciones laterales las cuales nos van a servir para otros injertos.

El injerto se talla en forma de L invertida uniendo dos fragmentos del mismo ${ }^{7}$, se fijan con prolene 5-0 con múltiples puntos (Figura 2) y se coloca suturado al septum, a los cartílagos laterales superiores y a la espina nasal anterior con prolene 5-0, lo cual brinda soporte a la estructura cartilaginosa y a su vez se consigue la rotación y proyección deseada.

Se disecan cruras mediales y laterales y se reseca el borde cefálico respetando entre 7 y $9 \mathrm{~mm}$. Se pasa punto interdomal con prolene 5-0 verificando que la porción anterior del injerto de banco en $\mathrm{L}$ invertida quede intercrural ${ }^{8}$, fijándose a las mismas para lograr mayor soporte de las estructuras septales. Se colocan láminas paraseptales de acetato fijadas con seda 2-0, taponamiento anterior con mechas y vendaje nasal con ferulización metálica. Las láminas paraseptales se dejan entre quince y treinta días de acuerdo con la integridad de la mucosa septal, la cual se lubrica durante ese período con triticumvulgare (fitoestimulina), promoviendo la epitelización del tejido.

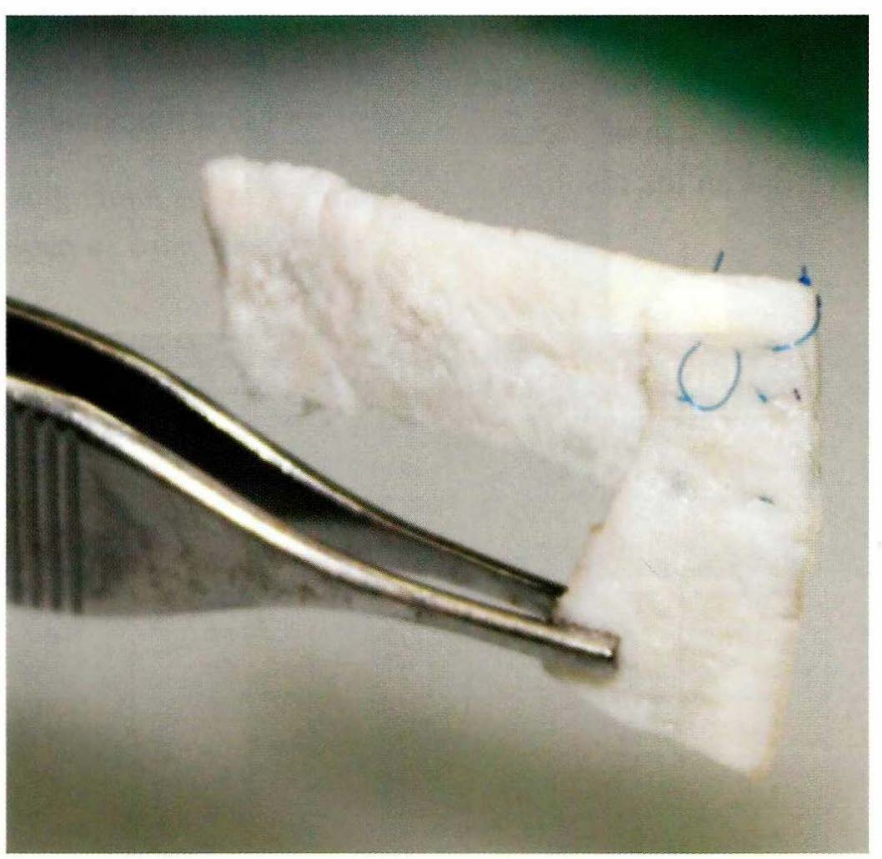

Figura 2. Injerto en $L$ invertida. 


\section{Resultados}

En el período de estudio ingresaron diez casos que cumplían los criterios de elegibilidad para el procedimiento, nueve hombres y una mujer. Siete tenían como antecedente trauma nasal, dos procedimiento quirúrgico y uno infeccioso. Las características de la población se describen en la Tabla 1. El tiempo mediano del procedimiento quirúrgico fue de cuatro horas.

No se documentaron complicaciones infecciosas tempranas (antes de 72 horas) ni tardías (seguimiento a siete meses). Tampoco hubo rechazo ni extrusión. Todos los pacientes manifestaron mejoríaclínica de la permeabilidad nasal exceptuando uno que refirió mejoría, pero presentaba síntomas de obstrucción nasal. Tenía antecedente de trauma y persistió con perforación septal después del procedimiento quirúrgico que logró disminuir el diámetro de la lesión de 2.5 a $0.5 \mathrm{~cm}$ (Figura 3). Un paciente presentó retracción de la columnela al cuarto mes posoperatorio sin limitación funcional pero con alteración en el ángulo nasolabial. Se ofreció corrección en un scgundo tiempo quirúrgico que el paciente no aceptó por encontrarse satisfecho con el resultado funcional y estético (Figura 4).

El resultado estético y funcional según el grado de satisfacción fue satisfactorio en ocho pacientes. Uno refirió estarlo pero la mejoría funcional no fue del $100 \%$ y persiste la obstrucción. Otro manifestó satisfacción estética a pesar de la retracción de la columnela y la restricción funcional. Las Figuras 3 a 7 comparan los resultados pre y posquirúrgicos.

\section{Discusión}

El tema de rinoplastia revisional cada día cobra más importancia por el incremento de la incidencia de pacientes insatisfechos. ${ }^{9} \mathrm{Al}$ revisar se advierten deficiencias importantes en cuanto a la evaluación y a la aplicación de técnicas demasiado agresivas que lesionan las estructuras cartilaginosas, dejando deformidades estéticas y alteraciones funcionales importantes. Se requiere, por tanto, retomar el estudio detallado al momento de evaluar una nariz, seleccionar con cuidado la técnica ${ }^{10}$ y en especial no agredir las estructuras, tratando de dejar mayor cantidad de tejido que a semiamputar los diferentes componentes estético funcionales.

Al presentar esta técnica proponemos que es adecuada para obtener resultados tanto estéticos como funcionales satisfactorios y es aplicable en todopaciente sin importar la etiología de la lesión. Con el injerto de cartîlago costal de banco de hueso se evita la necesidad de un segundo procedimiento quinúrgico para extraer injertos. ${ }^{11}$ Además no se presentó exurusión o infección en los pacientes. Con otras opciones quirúrgicas estas complicaciones son más frecuentes. ${ }^{12}$ Hay que identificar en la fase prequirúgica las alteraciones funcionales y estéticas para lograr un adecuadoplaneamiento de la intervención. ${ }^{13}$ El cartilago costal de banco de hueso evita el segundo procedimiento quirúrgico al paciente ${ }^{14} \mathrm{y}$ ha demos rado en la serie presentada lograr un adecuado soporte a la estructura nasal en todos los casos, con excelentes resultados funcionales y estéticos.

Nota: todas las fotografías tienen consentimiento escrito de los pacientes para su publicación científica.

\begin{tabular}{|c|c|c|c|c|c|c|c|c|c|}
\hline \multirow[b]{2}{*}{ Sexo } & \multicolumn{5}{|c|}{ Tipo de defecto } & \multirow[b]{2}{*}{$\begin{array}{l}\text { Colapso } \\
\text { alar }\end{array}$} & \multirow[b]{2}{*}{$\begin{array}{l}\text { Colapso } \\
\text { valvular }\end{array}$} & \multirow[b]{2}{*}{$\begin{array}{l}\text { Perforación } \\
\text { septal }\end{array}$} & \multirow[b]{2}{*}{$\begin{array}{c}\text { Ausencia } \\
\text { de borde } \\
\text { caudal }\end{array}$} \\
\hline & Edad & Laterorrinia & $\begin{array}{l}\text { Silla de } \\
\text { montar }\end{array}$ & $\begin{array}{l}\text { Obstrucción } \\
\text { nasal }\end{array}$ & $\begin{array}{l}\text { Cirugia } \\
\text { previa }\end{array}$ & & & & \\
\hline$M$ & 14 & sí & no & sí & no & sí & sí & no & sí \\
\hline$M$ & 12 & sí & no & si & no & no & no & no & sí \\
\hline $\mathrm{F}$ & 34 & sí & sí & sí & no & sí & sí & sí & sí \\
\hline$M$ & 46 & sí & no & si & si & sí & sí & no & sí \\
\hline$M$ & 51 & sí & no & sí & sí & no & sí & no & si \\
\hline$M$ & 56 & sí & sí & sí & no & no & no & sí & sí \\
\hline$M$ & 34 & sí & no & sí & no & no & no & no & sí \\
\hline
\end{tabular}



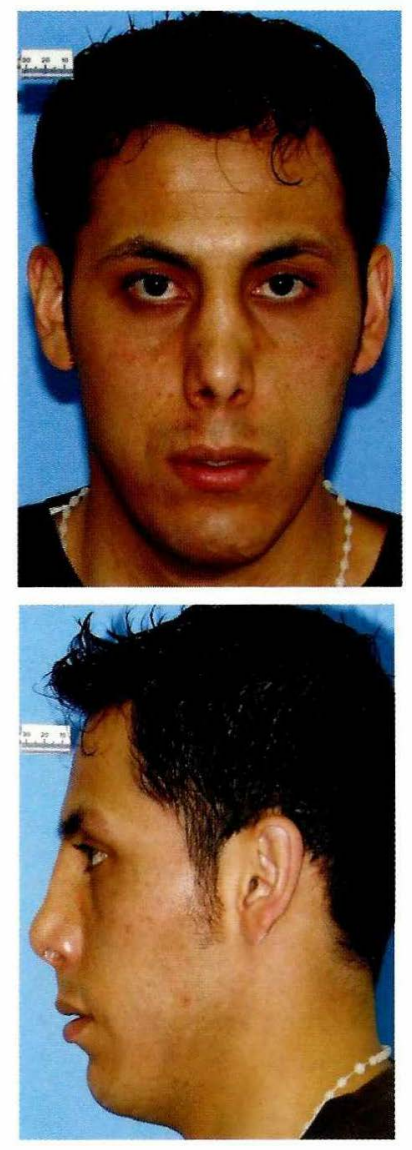

Figura 4. Comparaciones pre y postquirúrgicas.
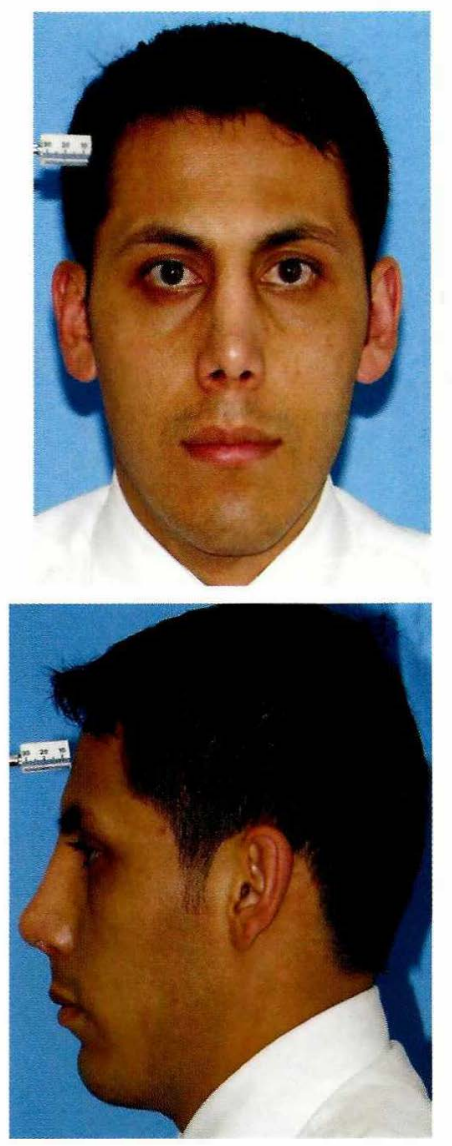

Figura 3. Comparaciones pre y postquirurgicas.
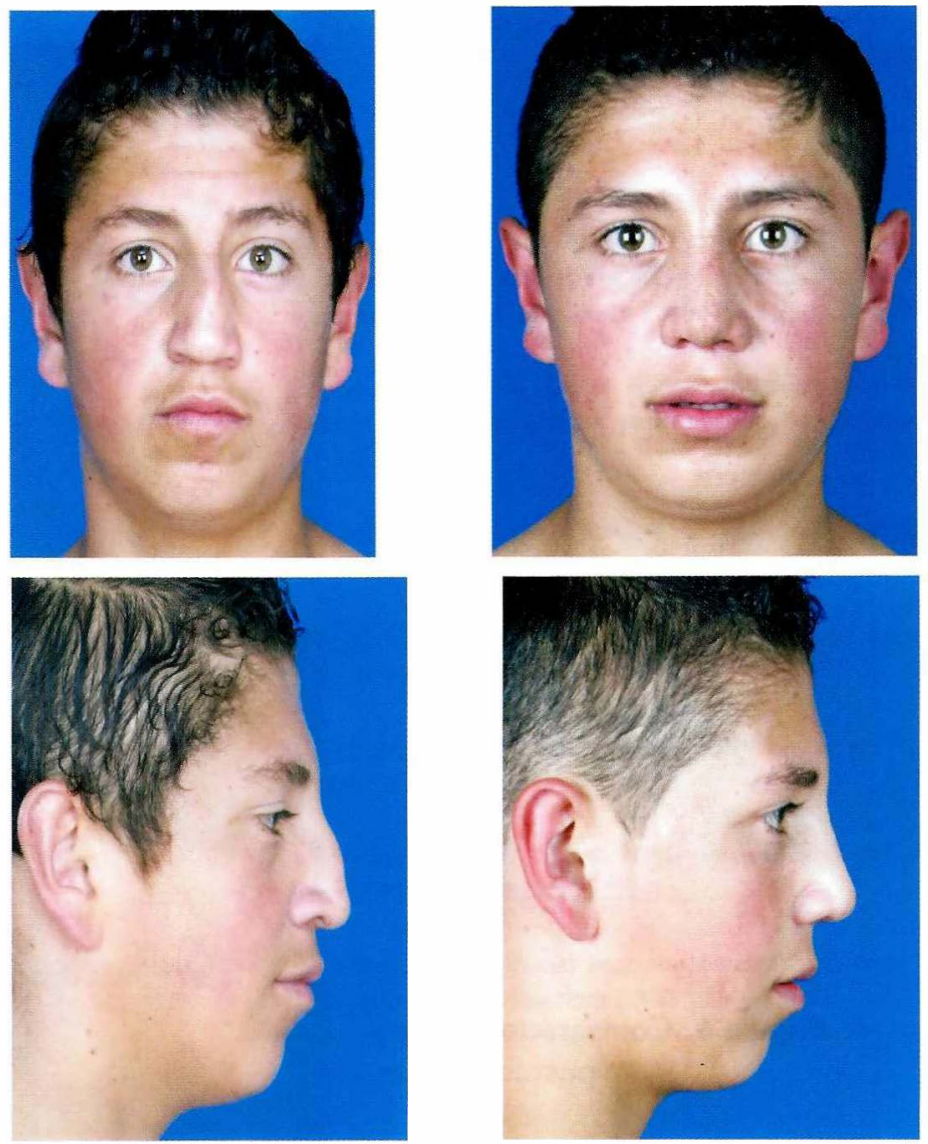

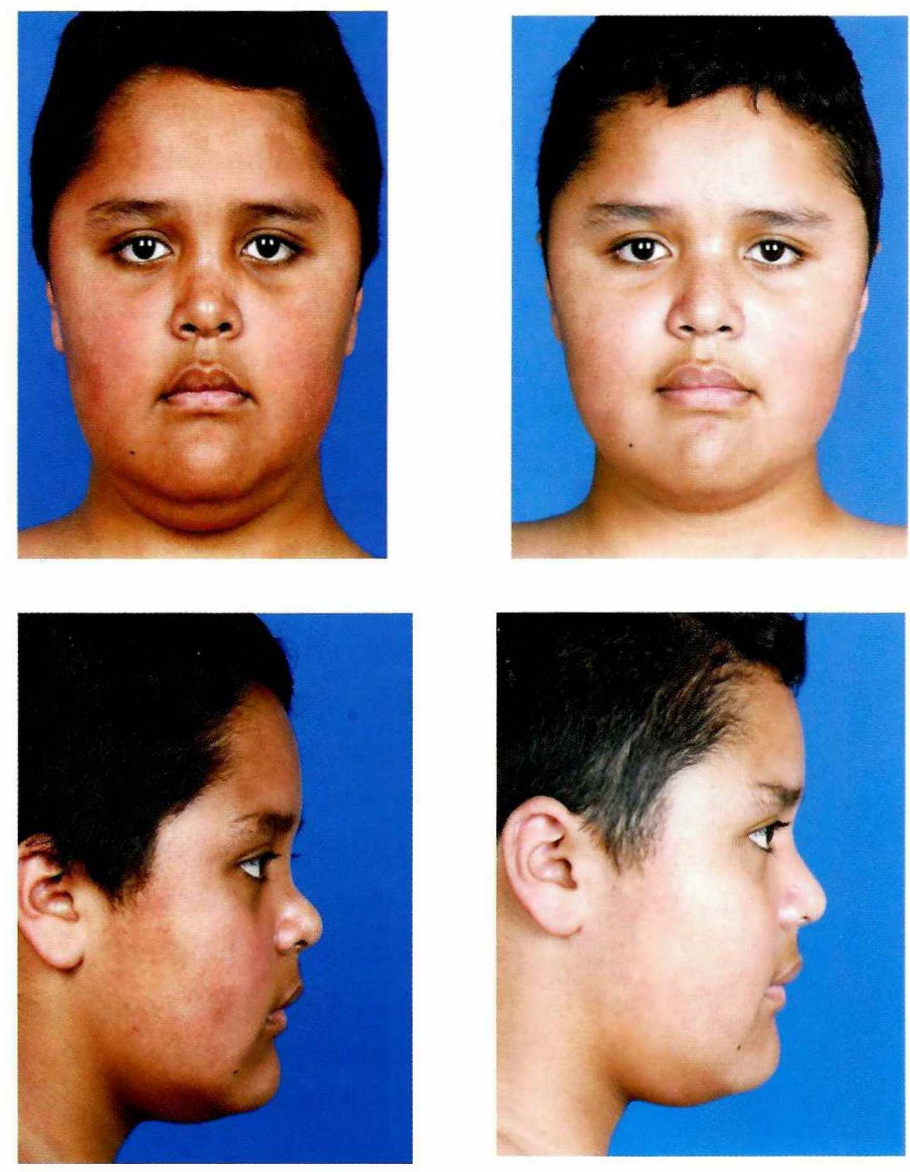

Figura 5. Comparaciones pre y postquirúrgicas.
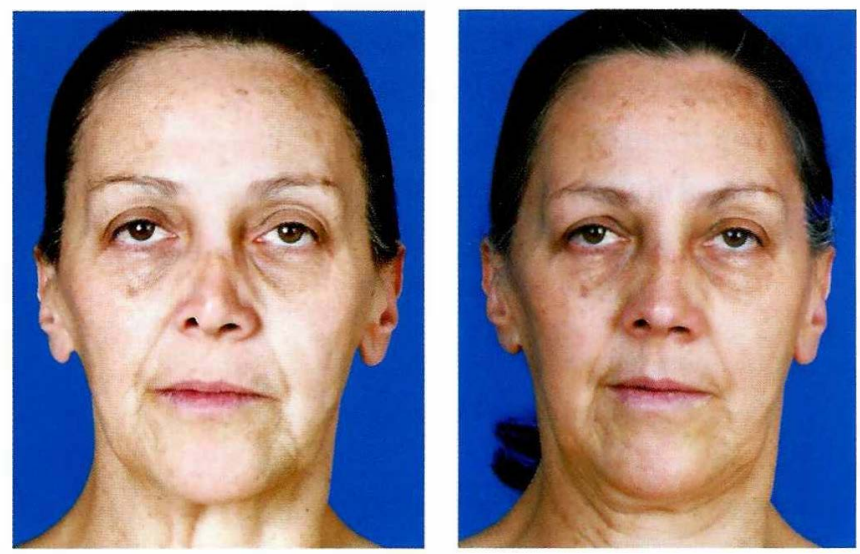

Figura 6. Comparaciones pre y postquirúrgicas.
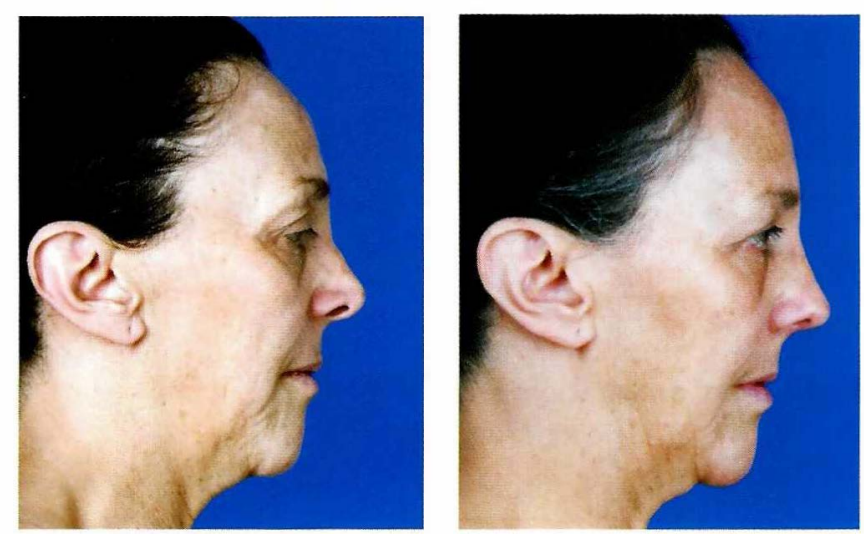

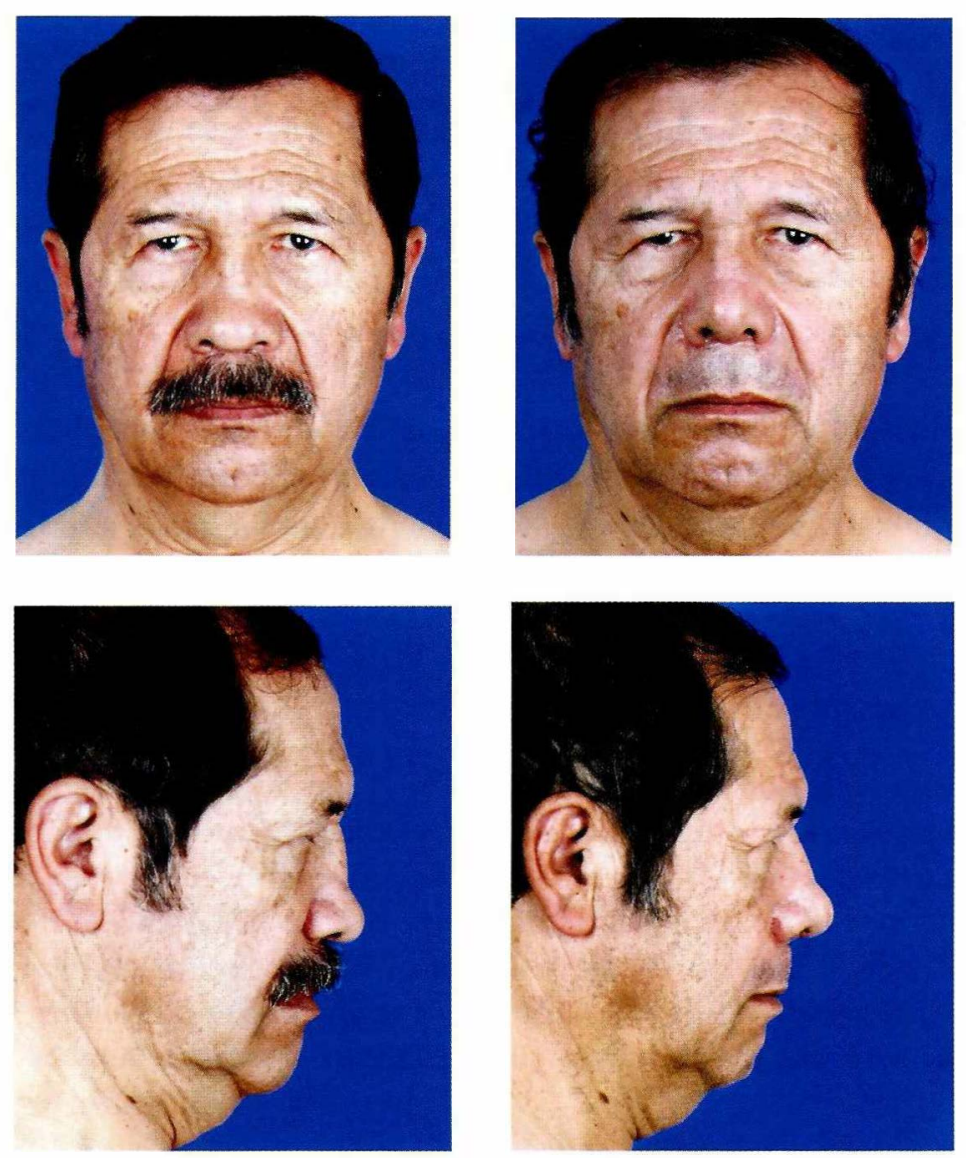

Figura 7. Comparaciones pre y postquirúrgicas.

\section{Referencias}

1. Defatta RJ, Williams EF. The decision process in choosing costal cartilage for use in revision rhinoplasty. Facial Plast Surg. 2008; 24(3): 365-71.

2. Paun SH, Nolst Trenité GJ. Revision rhinoplasty: an overview of deformities and techniques. Facial Plast Surg. 2008; 24(3): 271-87.

3. Kridel RW, Soliemanzadeh P. Tip grafts in revision rhinoplasty. Facial Plast Surg Clin North Am. 2006; 14(4): 331-41, vi.

4. Sandel HD, Perkins SW. Managernent of the short nose deformity in revision rhinoplasty. Facial Plast Surg. 2008; 24(3): 310-26.

5. Romo T, Kwak ES. Nasal grafts and implants in revision rhinoplasty. Facial Plast Surg Clin North Am. 2006; 14(4): 373-87, vii.

6. Fedok FG. Correction of dorsal abnormalities in revision rhinoplasty. Facial Plast Surg. 2008; 24(3): 327-38.

7. Paun SH, Nolst Trenité GJ. Revision rhinoplasty: an overview of deformities and techniques. Facial Plast Surg. 2008; 24(3): 271-87.
8. Defatta RJ, Williams EF. The decision process in choosing costal cartilage for use in revision rhinoplasty. Facial Plast Surg. 2008; 24(3): 365-71.

9. Yilmaz M, Vayvada $\mathrm{H}$, et al. Dorsal nasal augmentation with rib cartilage graft: long-term results and patient satisfaction. J Craniofac Surg. 2007; 18(6): 1457-62.

10. Nassif PS. Male revision rhinoplasty: pearls and surgical techniques. Facial Plast Surg. 2005; 21(4): 250-70.

11. Romo T 3rd, Kwak ES. Nasal grafts and implants in revision rhinoplasty. Facial Plast Surg Clin North Am. 2006; 14(4):373-87.

12. Bracaglia R, Fortunato R, et al. Secondary rhinoplasty. Aesthetic Plast Surg. 2005; 29(4):230-9.

13. Sherris DA, Kern EB. The versatile autogenous rib graft in septorhinoplasty. Am J Rhinol. 1998; 12(3):221-7.

14. Lefkovits G. Irradiated homologous costal cartilage for augmentation rhinoplasty. Ann Plast Surg. 1990; 25(4):317-27. 